\title{
Characteristics of Japanese Language Learners and Their Perceptions of Error Feedback
}

\author{
Noriko Fujioka-Ito \\ McMicken College of Arts and Sciences, University of Cincinnati, Cincinnati, Ohio, USA \\ Email: Noriko.Fujioka@uc.edu
}

\begin{abstract}
The studies in this article attempted to establish cross-validation of learners' perceptions of error feedback in both writing and oral activities by integrating educational psychological theories. Various factors could influence the effectiveness of error feedback in second language learning environments. Although the mode of feedback (i.e., oral or written) is also one of the factors influencing the effectiveness of error feedback, considerable research of both a descriptive and experimental nature has been done to examine the effects of error feedback on oral production (Russell \& Spada, 2006). Therefore, this article reports the statistical analysis results of an examination of the relationship between characteristics of learners and their perceptions of error feedback during both oral and writing activities, from social and individual learning perspectives. The study's findings could help teachers of Japanese as a second language develop appropriate methods of error feedback from students with different characteristics.
\end{abstract}

Index Terms — error feedback, learning styles, epistemological beliefs, classroom activities, writing activities

\section{INTRODUCTION}

Historically, studies on foreign language learners' errors and different types of error feedback have been discussed using contrastive analyses, error analyses, and performance analyses. All of these studies attempted to reveal learners' transfer processes from their native languages to their target languages or to detect their fossilization and find the reasons for the stabilization of structures and error making in the learning processes (Han \& Selinker, 1999). It has been pointed out that these analyses are limited from the psychological perspective. Recently, some researchers have examined teachers' perceptions of learners' responses to error feedback accurately and learners' noticing of their error feedback by recording learners' interaction and conducting a stimulated recall interview immediately after the completion of the task activities. However, learners' perceptions about the same classroom event differed considerably (Allwright, 1984; Slimani, 1989). Yet, individual student differences in response to error treatment have not received much attention though findings of this investigation could help teachers understand why some students make substantial progress whereas others respond less to feedback (Ferris, 2002).

Furthermore, learners' perceptions of error feedback seem to be influenced by the types of error feedback (e.g., Panova \& Lyster, 2002) during oral activities, implicating individual student variation in response to error correction; however, error feedback has not been seriously investigated in terms of writing activities (Ferris, 2002). Ellis (2008) pointed out the limitation of quantitative approaches, which do not provide researcher with detailed observation of learners in language-learning settings to examine individual differences. On the other hand, qualitative research method did not succeed in revealing learners' psychological states or learning strategies (Cohen, 1984; Rubin, 1975). Therefore, researchers prefer to use self-reports or triangulation (the use of several means to collect data and obtain reliable results) Nevertheless, only few qualitative studies have investigated individual difference because these studies are time consuming. This study attempted to provide an overview of learners' preferences for error correction methods using a larger number of subjects to establish higher reliability from quantitative research perspective.

Various factors could influence the effectiveness of error feedback in second language learning environments. These factors include not only the type, amount, and source of correction, but also learners' characteristics, such as attitudes towards correction, aptitude, motivation, and anxiety. Although the mode of correction (i.e., oral or written) is also one of the factors that affect the effectiveness of error feedback, considerable research of both a descriptive and experimental nature has been done to examine the effects of error feedback on oral production (Russell \& Spada, 2006). The studies in this article were conducted based on the hypothesis that learners' perceptions of error feedback in writing activities should be related more to individual learning factors (which could elicit learners' preferences, tendencies, and habits while accounting for individual differences in learning) than to learning styles (which identify learners' preferences for interacting with peers and the instructor in classroom settings), though individual and social perspectives are not completely independent in classroom learning settings (see the next section). This article reports two studies on learners perceptions of error feedback during both oral and writing activities assessing (a) the degree to which learning styles, epistemological beliefs, and demographic information influence learners' perceptions of error feedback and (b) the relationships between learners' characteristics and their attitudes toward error feedback. 


\section{Perception of Error FeEdback in a Social vs. Individual EnTity}

Two studies reported in this article examined whether learning style characteristics influences learners' perceptions of error feedback more during oral compared to writing activities, which involve more internal preferences and learning processes. According to the social learning theory, the social situation can influence individual learners, though the degree of active social mediation varies from situation to situation. According to the individual learning theory, others can facilitate individuals' learning through participating in the collective learning. It is important to understand how individual and social learning relate to one another. The combination of the first theory of learning (focusing on individual learning in the socially mediated situation) and the second theory of learning (focusing on individual participation in the learning of a collective) builds a "reciprocal spiral relationship" (Salomon \& Perkins, 1998).

Ellis (1994) described three sets of variables, (a) individual leaner differences, including beliefs about language learning, affective states, and general factors, (b) learners' strategies, and (c) language learning outcomes, all of which are interrelated in the process of learning. As Ellis claimed, one of the goals of research with regard to individual differences is to identify the nature of these interrelationships, to identify each learner's style and beliefs about learning, and to consider factors (e.g., individual learning systems or social constructions) that influence the classroom, thus helping teachers to solve problems effectively. Therefore, Japanese language classes for non-native speakers should benefit from identifying individual learners' dispositions, including learning styles and beliefs about learning, and examining the relationship between various styles and beliefs.

Some studies have shown that learning styles affect the learners' perceptions of error feedback in the classroom. For example, Crichton (1990) revealed that peer correction turned out to be problematic. In his study, problems arose when peer correction caused humiliation, resulting in a crisis at the elementary proficiency level. This situation tends to occur if the majority of learning styles in a class are competitive. In the two studies discussed in this article, the GrashaRiechmann Student Learning Style Scales (GRSLSS) (1994), namely (a) Independent, (b) Avoidant, (c) Collaborative, (d) Dependent, (e) Competitive, and (f) Participant, were used to identify learning styles in the classroom. The participants in their study responded 60 questions - 10 questions assessing each learning style - measured on a fivepoint Likert scale. This instrument, developed based on a large number of informal observations of how students approached classroom tasks (Grasha, 1972), has been used in higher education for more than two decades (Grasha, 1996). The original formulation of the six learning styles suggested that Competitive-Collaborative, AvoidantParticipant, and Dependent-Independent were bipolar or represented three pairs of dichotomies. However, Grasha (1996) reported that using the Grasha-Riechmann Student Learning Style Scales showed that only the Avoidant-Participant dimensions represent a dichotomy $[\underline{r}=-.69$ to -.75] but not Competitive-Collaborative and Dependent-Independent dimensions [r=-.22 to -.33].

To identify learners' multidimensional beliefs about the acquisition of knowledge, Shommer (1998a) used the epistemological beliefs questionnaire, which elicits learners' preferences, tendencies, and habits, and accounts for individual differences in learning, was used. Schommer (1989) developed a questionnaire designed to reveal whether the subjects are naïve or sophisticated learners based on the five epistemological components that, in her hypothesis, affected learning. Naïve learners believed that most knowledge is absolute and that the remainder of knowledge is temporarily unknown. In contrast, sophisticated learners are more skeptical when soliciting information. In her 1989 study, Schommer examined differences between junior-college students and university students in their beliefs about learning. The results of this study showed that university students were more likely to believe in innate ability and that junior-college students were more likely to believe in simple knowledge, certain knowledge, and quick learning. In 1990, Schommer analyzed the same data using factor analysis. In this analysis, simple knowledge and quick learning had a strong effect on their beliefs. None of the variables surveyed predicted belief in certain knowledge. This result also suggested that exposing students to more advanced knowledge facilitated a change in belief systems with regard to the uncertainty of knowledge. Thus, studies on epistemological beliefs could identify some critical sources of the problem and guide researchers, educators, and learners in modifying instruction to make it more suitable for learners' varying ways of acquiring knowledge (Schommer-Aikins, 2001). The results of some studies showed statistically significant relationships between epistemological beliefs and conceptions of learning (e.g., Chan, 2007). Schommer's epistemological beliefs questionnaire consists of 63 questions categorized into 12 subsets of items: (a) seek single answers, (b) avoid integration, (c) avoid ambiguity, (d) depend on authority, (e) knowledge is certain, (f) don't criticize authority, (g) ability to learn is innate, (h) can't learn how to learn, (i) success is unrelated to hard work, (j) learn the first time, (k) learning is quick, and (l) concentrated effort is a waste of time. The responses are measured on the same five-point scale as the GRSLSS.

\section{PURPOSES OF THE STUDIES}

The two studies discussed in this article were conducted for the following purposes:

1. To investigate the relationships between learners' characteristics (learning styles and epistemological beliefs) and their attitudes towards error feedback during both oral and writing activities. 
2. To examine whether learning style characteristics on class structure influence learners' perceptions of error feedback more during oral activities than during writing activities, which involve more internal preferences and learning processes.

3. To recommend to teachers of Japanese as a second language appropriate methods of providing error feedback to students with different learning characteristics when engaging in both speaking and writing activities.

\section{STUDY ONE}

The first study examined learners' perceptions of error feedback during oral activities. The following section reports the design of the study, data analysis and results.

\section{A. Participants and Procedure}

Students enrolled in all levels ${ }^{1}$ of Japanese language courses at eight universities in the United States participated in Study 1. Two-hundred-fifteen questionnaires were statistically analyzed. It was expected that the characteristics of teachers affect learners' perceptions in the classroom; therefore, only universities where native Japanese instructors teach were selected to make the participant sites homogeneous. The students participating in this study volunteered to participate and completed a demographic questionnaire (reporting demographic information such as gender and major) and three instruments. All participants were provided with explicit directions on how to respond. The instructors participating in this study were notified that they should allow approximately fifteen minutes for the completion of the survey. After the completion, the questionnaires were returned to the investigator for analysis.

\section{B. Survey Instrument}

To investigate the relationship between learners' characteristics and their perceptions of error feedback, the survey instrument comprised four parts, corresponding to four different learning characteristics: (a) demographic information (Gender, Race, School year, Major, Native language, Proficiency level, Japanese class size), (b) attitudes toward error feedback (Appendix A), (c) GRSLSS (learning style questionnaire), and (d) Schommer's epistemological belief questionnaire.

The survey on attitudes toward error feedback that investigates learners' perspectives toward error treatment during oral activities was developed based on the review of studies on error treatment. The first question revealed the learners' preference for error correction during oral activities in the classroom overall. The second question attempted to find the preference for error correction source among teachers, peers, or individual selves and confirmed some research findings that peer correction and self-correction were problematic because error treatment involves socio-cultural factors, such as social strain, embarrassment, humiliation, or confusion in a classroom (Breen, 2001; Crichton, 1990; van Lier, 1988). The third question examined learners' attitudes toward self-correction without considering interactions with peers. Language learners, especially at the lower proficiency level, need "other-regulation" to reach the automatized selfregulation level. However, this "other-regulation" refers to the teacher, not to the peer, because peer correction involves problems, such as the ambiguity of error treatment (Crichton, 1990). Vygotsky's "zones of proximal development(ZPD) and the effect of reformulation (Nobuyoshi \& Ellis, 1993) have supported the importance of self-regulation. Vygotsky showed that self-regulation develops gradually with the support of a tutor in the notion of ZPD. Nobuyoshi and Ellis also showed that their experimental group, which received requests for clarification every time they produced an incorrect utterance of the specific learning grammatical item, produced fewer errors.

The fourth question sought to determine whether the learners preferred to receive the error treatment immediately after making an error or after finishing a conversation during oral activities, though pedagogical consideration has been given to the question of when errors should be corrected and when they should be ignored. The choices to the fifth question, which asked participants on what kind of classroom activity they wanted to receive the error correction most, were made based on a continuum between discrete-point and global and between discrete-point and integrative axes (Savignon, 1983). According to the two-dimensional plot based on Savignon's classification, four activities, (a) pronunciation practice, (b) grammar practice, (c) skit, and (d) free conversation (pronunciation practice and grammar practice are more discrete-point activities, whereas skit and free conversation are more integrative and global activities), were selected to investigate the relationships between learners' individual factors (their styles and beliefs of learning) and types of classroom activities (discrete-point/integrative or discrete-point/global).

The sixth question asked what kinds of error learners think should be corrected in class. This question categorized errors into intelligible, acceptable, and correct, paralleling van Lier's (1988) classification of errors. Preferences for one kind of error treatment were examined in light of the learners' beliefs (e.g., tolerance of ambiguity) toward learning. The seventh question investigated for what grammatical items learners wanted to receive the error correction. Based on Savignon's (1983) model used for the fifth question, five grammatical items, (a) pronunciation, (b) particles, (c) conjugation of verbs or adjectives, (d) usage of words, and (e) logical coherence (pronunciation, particles, and more conjugation of verbs or adjectives are more discrete-point items, whereas usage of words and logical coherence are

\footnotetext{
${ }^{1}$ Low (107 students, 50\%), Intermediate (63 students, 29\%), High (45 students, 21\%). Proficiency levels were not assessed. The categorization of proficiency levels were determined based on hours that learners were given in class; i.e., Low (less than 150 hours), Intermediate (between 150 and 300 hours), and High (more than 300 hours).
} 
integrative and global items), were selected to investigate the relationships between learners' individual factors (their styles and beliefs of learning) and types of grammatical items (discrete-point/integrative or discrete-point/global). The eighth question examined what kind of correction learners prefer to receive after making their errors. The choices to the eighth question were based on four types of error treatment in Carroll and Swain's (1993) experiment. They were (a) explicit metalinguistic information, (b) inaccurate information without any explanations, (c) a model of the response with implicit negative evidence, and (d) a confirmatory check.

\section{Data Analysis}

The survey data was statistically analyzed in two parts.

Part 1: The first analysis identified the learning styles and the epistemological beliefs of participants in Study 1 using factor analyses.

Part 2: The second part examined the relationship between learners' characteristics and their perceptions of error feedback using logistic regression analyses ${ }^{2}$ and correlation analyses.

\section{Results}

Study One Part 1: Learning Styles.

A principal factor extraction with promax rotation generated six factors that had a factor loading greater than or equal to .35 or less than or equal to -.35. The six learning styles found in this study were (1) Avoidant, (2) Collaborative, (3) Competitive, (4) Independent, (5) Diligent, and (6) Dependent. The five factors (Avoidant, Collaborative, Competitive, Independent, and Dependent), except Diligent learning style factor, are named after five of the Grasha-Riechmann's (1994) six learning styles.

Study One Part 1: Epistemological Beliefs.

The data collected from the epistemological beliefs questionnaire were analyzed using factor analysis. A principal factor extraction with promax rotation generated four factors with factor loadings greater than or equal to .35 or less than or equal to -.35. The four epistemological beliefs found in this study were (1) Building-Up Ability, (2) Quick Learning, (3) Certain Knowledge, and (4) Simple Knowledge. Three out of four factors in the present study were identical to the Schommer's (1989) five epistemological dimensions ${ }^{3}$. Although Schommer originally named the Quick Learning, Certain Knowledge, and Simple Knowledge factors, the Building-Up Ability factor concerns beliefs, which contradicts Schommer's Innate Ability factor. That is, the Building-Up Ability factor does not reflect the abilities that are fixed at birth; instead, it is a new dimension found in this study.

\section{Study One Part 2}

The second half of the statistical analysis revealed that (a) survey respondents' perceptions of learning can be examined both as a social entity and separately as an individual entity and that (b) the degree of dependence of learning style characteristics on class structure influences learners' attitudes towards error feedback, whereas the degree of dependence of these beliefs on class structure does not affect students' attitudes.

Social constructions in the classroom that influenced more heavily the relationship between various factors relating to different learners and responses to error feedback questions are shown in Table 1. In this study, Questions 1-8 (examining learners' perceptions of error feedback) were influenced by social constructions in the classroom (Questions 1-3 and 5) and by internalized processes in individual learning (Questions 4 and 6-8). The results of this study showed that social learning styles, as measured by GRSLSS (1994), relate more closely to students' perceptions of social aspects of classroom activities than to epistemological beliefs (1989) (see Table 1).

First, the findings revealed an overall positive attitude toward error feedback. Ninety-nine percent of the survey participants self-reported positive attitudes toward error feedback. However, additional examination revealed that the competitive learning style correlated negatively with learners' attitudes toward error feedback $(\underline{\mathrm{r}}=-.15, \underline{\mathrm{p}}<.05)(\mathrm{Question}$ 1). The majority of the learners exhibited a preference for error correction by instructors (Instructor=79\%; Fellow students $=7 \%$; Yourself $=14 \%$ ). Statistical analysis showed no difference between subjects who preferred error correction by instructors and those who preferred self-correction in learning styles. However, correlation analysis and logistic regression analysis comparing the six learning styles and error correction by fellow students revealed that the

\footnotetext{
${ }^{2}$ The dependent variables of the error correction survey are dichotomous or polytomous nominal variables; thus, logistic regression analysis rather than other types of regression analyses was performed.

${ }^{3}$ The difference between Schommer's consistent results of factor analyses and those of the present study might be produced by different characteristics of the samples or different calculation methods of factor score coefficient. Schommer has suggested that this epistemological questionnaire was only applicable if the sample was similar to the sample of people who participated in Schommer's earlier studies. Yet, because of the nature of Japanese language classes, not only white students but also students from other racial heritages, especially Asian, were enrolled in these classes in all universities that participated in this study. Another reason for the discrepancies between the results of Schommer's studies and this study was that Schommer used a priori subsets of belief dimensions as original variables, whereas this study used individual items as original variables.
} 
TABLE 1

THE RELATIONSHIP BETWEEN LEARNERS' FACTORS RELATED TO LEARNING (LEARNING STYLES AND EPISTEMOLOGICAL BELIEFS) AND ERROR FEEDBACK QUESTIONS DURING ORAL ACTIVITIES INFLUENCED MORE BY SOCIAL CONSTRUCTIONS IN THE CLASSROOM

\begin{tabular}{|c|c|c|}
\hline Error Correction Question & $\begin{array}{l}\text { Significant Result } \\
\text { Learning Style }\end{array}$ & Ep istemological Be lief \\
\hline \multicolumn{3}{|c|}{$\begin{array}{c}\text { Q1: Do you usually want to receive consis tent correction of your errors? (Yes } 99 \% \text {, No } 1 \% \text { ) } \\
-{ }^{b} \text { Competitive }\end{array}$} \\
\hline \multicolumn{3}{|c|}{$\begin{array}{l}\text { Q2: When your errors are corrected, from whom do you generally prefer to receive the error correction? } \\
\text { (Instructor } 79 \% \text {, Fellow students } 7 \% \text {, Yourself } 14 \% \text { ) }\end{array}$} \\
\hline Fellow Students & - Dependent & \\
\hline \multicolumn{3}{|c|}{$\begin{array}{l}\text { Q3: After your instructor states that your utterances were incorrect, do you want to correct them by yourself } \\
\text { (Yes } 86 \% \text {, No } 14 \% \text { ) }\end{array}$} \\
\hline & $\begin{array}{l}+{ }^{\mathrm{a}} \text { Competitive } \\
+ \text { Independent } \\
+ \text { Diligent }\end{array}$ & \\
\hline \multicolumn{3}{|c|}{$\begin{array}{l}\text { Q5: During what kind of classroom activity do you most want to receive the error correction? } \\
\text { (Pronunciation practice } 17 \% \text {, Grammar practice } 52 \% \text {, Skit } 7 \% \text {, Free conversation } 24 \% \text { ) }\end{array}$} \\
\hline Pronunciation & - Dependent & \\
\hline Grammar & $\begin{array}{l}+ \text { Diligent } \\
+ \text { Dependent }\end{array}$ & + Building-Up \\
\hline Skit & + Collaborative & \\
\hline Free Conversation & & - Building-Up \\
\hline
\end{tabular}

Note. +a indicates positive attitudes. -b indicates negative attitudes.

dependent learning style correlated negatively with error corrections made by fellow students $(\underline{r}=-.15)$ at $\underline{\mathrm{p}}<.05$ (Question 2). Correlation analysis showed three positive relationships between competitive, independent, and diligent learning styles and the preference for self-correction ( $\mathrm{r}=.16, \mathrm{p}<.05 ; \underline{\mathrm{r}}=.17, \mathrm{p}<.05 ; \underline{\mathrm{r}}=.21, \mathrm{p}<.01$, respectively), although, for Question 2, the results revealed no relationship between learning styles and a preference for self-correction (Question 3). Question 5 sought to determine how learners react to a social entity. The results revealed that learners who had a belief in building-up ability, which is one of the epistemological beliefs found in this study, preferred error correction during discrete-point classroom activities (e.g., grammar practice)( $\mathrm{r}=.19, \mathrm{p}<.01,2.2$ times higher odds $\left[\mathrm{Q}_{\mathrm{w}}\right.$ $=5.334, \underline{\mathrm{p}}<.05])$ and disliked receiving correction during global and integrative activities (e.g., free conversation) $(\underline{r}=-.22$, $\mathrm{p}<.01,3.0$ times lower odds $\left.\left[\mathrm{Q}_{\mathrm{w}}=7.611, \mathrm{p}<.01\right]\right)$. This result can be interpreted that learners who have the building-up ability belief are willing to receive grammatical error correction and develop their linguistic accuracy though they do not like receiving error feedback during free conversation. Learners with the dependent learning style did not prefer to receive error correction during pronunciation practice $\left(\underline{r}=-.13, \underline{p}<.05,2.5\right.$ times lower odds $\left.\left[\mathrm{Q}_{w}=5.014, \underline{p}<.05\right]\right)$, whereas those who had the diligent and dependent styles showed positive attitudes towards error correction during grammar practice $\left(\mathrm{r}=.14, \mathrm{p}<.05\right.$ [Diligent] $; \underline{\mathrm{r}}=.20, \underline{\mathrm{p}}<.01,2.5$ times higher odds $\left[\mathrm{Q}_{\mathrm{w}}=5.871, \mathrm{p}<.05\right.$ [Dependent]).

Study 1 showed that Schommer's epistemological beliefs questionnaire provided a more effective measurement of individual dispositions about how to acquire knowledge rather than social construction (responses to Questions 4 \& 6-8 are affected by learners' beliefs) (see Table 2). The proportion of learners preferring immediate correction (77\%) exceeded that of delayed correction (23\%); however, correlation analysis or logistic regression analysis did not find statistical significance (Question 2). Both correlation analysis and logistic regression analysis showed that collaborative learners preferred to receive correction for incomprehensible errors $\left(\mathrm{r}=.19, \mathrm{p}<.01,2.7\right.$ times higher odds $\left[\mathrm{Q}_{\mathrm{w}}=11.639\right.$, $\mathrm{p}<.001][$ Collaborative]). On the other hand, students with the collaborative learning style do not prefer to receive correction when errors are acceptable and comprehensible but ungrammatical ( $\mathrm{r}=-.22, \mathrm{p}<.01$ [Collaborative] 3.4 times lower odds $\left[\mathrm{Q}_{\mathrm{w}}=14.19, \mathrm{p}<.001\right]$ [Collaborative]). The relationship between learning styles and the kinds of errors (incomprehensible errors, unacceptable errors, and ungrammatical errors) for which learners wished to be corrected was contradictory. Learners who possessed the collaborative learning style wished to be corrected when the errors were incomprehensible but acceptable and comprehensible although ungrammatical. The three kinds of targeted errors in Question 6 that students feel are acceptable become gradually more distinct; in other words, the first choice, that is, incomprehensible errors, is the least precise choice while the last choice, that is, ungrammatical errors, is the most precise choice. Therefore, the result (i.e., learners with the collaborative learning style want their incomprehensible and ungrammatical errors corrected, but they do not want to receive unacceptable error correction) is unreasonable. The 
TABLE 2

THE RELATIONSHIP BETWEEN LEARNERS' FACTORS RELATED TO LEARNING (LEARNING STYLES AND EPISTEMOLOGICAL BELIEFS) AND ERROR FEEDBACK QUESTIONS DURING ORAL ACTIVITIES INFLUENCED BY INDIVIDUAL LEARNERS’ INTERNALIZING PROCESSES

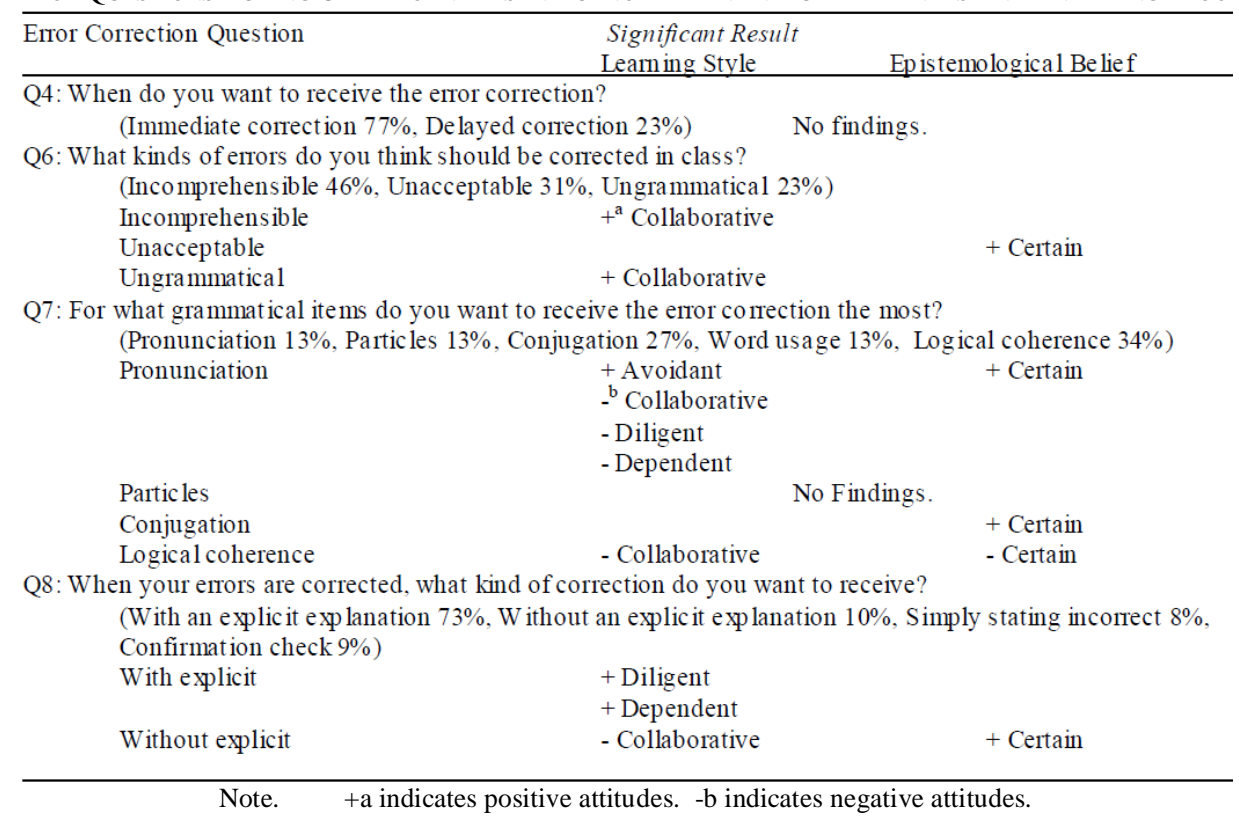

students who believe in the building-up ability prefer to receive feedback only for unacceptable errors (Positive $[\mathrm{r}=.15$, $\mathrm{p}<.05], 1.8$ times higher odds $\left[\mathrm{Q}_{\mathrm{w}}=3.541, \mathrm{p}<.05\right]$ ), even if those errors are comprehensible (Question 6).

In Question 5, it was found that students with the learning styles that were more dependent on teachers preferred to receive error feedback during discrete-point classroom activities, whereas more collaborative and diligent learners did not want their errors corrected during global and integrative activities, such as fee conversation. Regarding the types of errors for which the learners wanted to receive feedback, the results of the correlation analysis and the logistic regression analysis pertaining to Question 7 showed a positive correlation between the avoidant learning style and error feedback for pronunciation $(\mathrm{r}=.20, \mathrm{p}<.01)$ and negative correlations between three learning styles (Collaborative, Diligent, and Dependent) and error feedback for pronunciation ( $\mathrm{r}=-.15, \mathrm{p}<.05$ [Collaborative]; $\mathrm{r}=-.16, \mathrm{p}<.05$ [Diligent]; $\underline{\mathrm{r}}=-.22, \mathrm{p}<.01$ [Dependent]). In addition, there was a negative correlation between the collaborative learning style and error feedback for logical coherence (1.8 times lower odds $\left.\left[\mathrm{Q}_{\mathrm{w}}=14.19, \mathrm{p}<.001\right]\right)$. However, this result contradicted the assumption that different learning styles change learners' preferences for receiving error correction for discrete-point items or for more integrative and global items because the collaborative learning style was negatively correlated negatively with both error feedback for logical coherence (an integrative and global item) and error feedback for pronunciation (a discrete-point item). The relationship between learners' epistemological beliefs and grammatical items that learners wished to have corrected showed that a gradual development of beliefs from absolute to tentative changes the learners' preferences for receiving error feedback from more discrete-point items, such as pronunciation (Positive $[\underline{r}=.14, \underline{p}<.05]$ [Certain]), to more integrative and global items, such as logical coherence (Negative [ $\underline{r}=-.15, \underline{p}<.05], 2.1$ times lower odds $\left[\mathrm{Q}_{\mathrm{w}}=5.185, \mathrm{p}<.05\right][$ Certain]) (Question 7).

The proportion of respondents who preferred error feedback with an explicit explanation versus the proportion of those who prefer other types of error feedback (With an explicit explanation $=73 \%$, Without an explicit explanation $=10 \%$, Telling incorrect $=8 \%$, Confirmation check=9\%), the majority of learners wanted to receive explicit explanations when they received error feedback. Comparing error feedback without explicit explanation and error feedback with explicit explanation revealed that error feedback with explicit explanation is better because learners can internalize the concept with the explanation, facilitating the development of their language abilities. Study 1 showed that students with the diligent learning style and the dependent learning style preferred error feedback with explicit explanation ( $\mathrm{r}=.15, \underline{\mathrm{p}}<.05$ [Diligent]; $\mathrm{r}=.16, \mathrm{p}<.05$ [Dependent]). It was also found that learners who had the collaborative learning style did not prefer to receive error feedback without explicit explanation $(\underline{\mathrm{r}}=-.20, \mathrm{p}<.01,2.2$ times lower odds $\left.\left[\mathrm{Q}_{\mathrm{w}}=4.1211, \mathrm{p}<.05\right]\right)$. Although correlation analysis and logistic regression analysis showed a positive relationship between certain knowledge belief and error feedback without explicit explanation $(\underline{r}=.15, \underline{p}<.05,3.0$ times higher odds $\left[\mathrm{Q}_{\mathrm{w}}=3.046, \mathrm{p}<.05\right]$ ), they did not show statistically significant relationship between the building-up ability belief and confirmation check (Question 8).

\section{STUdy Two}


Study 2 was conducted for the purposes of (a) investigating learners' perceptions of error feedback in writing activities, replicating the scope of Study 1 regarding oral activities and (b) examining whether writing activities involve more internal preferences and learning processes rather than oral activities.

\section{A. Participants and Procedure}

Students who were enrolled in all levels ${ }^{4}$ of Japanese language courses in a Mid-west university in the United States participated in Study 2. Ninety-nine questionnaires were statistically analyzed following the same procedures as in Study 1.

\section{B. Survey Instrument}

To investigate the relationship between learners' characteristics and their perceptions of error feedback during writing activities, the same types of questionnaires were used as in Study 1. They included (a) demographic information (same information was asked as Study 1), (b) attitudes towards error feedback (Appendix B), (c) GRSLSS (learning style questionnaire), and (d) Schommer's epistemological belief questionnaire.

The same as the error correction survey in Study 1, the questionnaire on attitudes toward error feedback, which investigates learners' perspectives toward error feedback in writing activities, was constructed based on previous studies. The first, second, third, and eighth question in Study 2 were the same as the first, second, sixth, and eighth question in Study 1, respectively. They compare learners' perspectives of error feedback during oral activities versus writing activities. The fourth question in Study 2 parallels the fifth question in Study 1. The choices of the fourth question that sought learners' preference for error correction on the two-dimensional plot based on Savignon's (1983) classification resembled the fifth question in Study 1. Spelling and punctuation are more discrete-point items, whereas word usage and logic are more integrative and global items. The fifth question in Study 2 measured the degree of learners' abilities of self-regulation, similar to the third question in Study 1, developed based on Kubota's (2001) study that investigated strategies used for self-correction. The choice "ask teacher for help" indicates that learners rely on "other-regulation" whereas the choice "check a dictionary" or "check a textbook" indicates a higher degree of "self-regulation." The sixth and seventh questions sought learners' preferences for coding systems based on previous studies, which examined the effectiveness of the coding system and the existing error correction in writing practices (e.g., Kubota, 2001; Lee, 1997, 2004). In Study 2, Question 2 was the question seeking how learners react to social aspects, whereas responses to Questions 1 and 3-8 were questions affected by internalized processes in individual learning.

\section{Data Analysis}

As in Study 1, the survey data was statistically analyzed in two parts.

Part 1 of Study 2 used factor analysis to identify the learning styles and epistemological beliefs of participants.

Part 2 of Study 2 examined the relationship between specific characteristics of learners and their perceptions of error feedback using logistic regression ${ }^{1}$ and correlation analyses.

\section{Results}

Study Two Part 1: Learning Styles.

A principal factor extraction with varimax rotation generated six factors that had a factor loading greater than or equal to .35 or less than or equal to -.35: (a) Collaborative, (b) Avoidant, (c) Competitive, (d) Diligent, (e) Independent, and (f) Dependent. The characteristics of these six learning styles are as follows. Collaborative learning style learners are concerned with a cooperative manner and like to learn by interacting with others. Avoidant learning style learners participate in class unwillingly and dislike learning in general. Learners with the competitive learning style believe that it is necessary to compete with other students for rewards. Diligent learning style learners possess a serious attitude towards the completion of any work. Independent learning style learners prefer to learn the content that they themselves feel is important and prefer to work alone. Learners who have the dependent learning style believe that learning should rely on their teacher and peers. These learning styles and bipolar relationships among learning styles were consistent with the results of Study 1 in terms of error feedback during oral activities.

Study Two Part 1: Epistemological Beliefs.

The data collected from the same participants using the epistemological questionnaire were analyzed using factor analysis that used a principal factor extraction with promax rotation with a .35 factor loading cutoff point. Four epistemological beliefs were found in this study: (a) Building-Up Ability, (b) Fixed Ability, (c) Profound Knowledge, and (d) Certain Knowledge. The dispositions of four epistemological beliefs are as follows. Learners who have a belief in building-up ability believe that knowledge builds up through complex processes over a long period. Fixed Ability belief is relatively similar to "Innate Ability" originally named by Schommer (1989), which is a belief that abilities are determined at birth. Learners who possess a belief in fixed ability believe that knowledge and ability are fixed from the birth. Learners with a profound knowledge belief believe that knowledge is acquired profoundly and is not characterized as knowing isolated facts. Learners with a belief in certain knowledge believe that knowledge is certain

\footnotetext{
${ }^{4}$ Low (76 students, 77\%), Intermediate (14 students, 14\%), High (9 students, 9\%). Proficiency levels were not assessed. The categorization of proficiency levels was determined using the same method as described in Note 1.
} 
and absolute. Two out of the four factors were the same as in the study regarding oral activities. Study 1 examined quick learning and simple knowledge beliefs whereas Study 2 examined fixed ability and profound knowledge beliefs.

Study Two Part 2: The Relationship between Learning Styles and Learners' Perceptions of Error Feedback.

Correlation analyses and logistic regression analyses examined the relation between learning styles and learners' perceptions of error feedback, revealing three findings (see Table 3 and 4).

First, the findings revealed an overall positive attitude toward error feedback (Question 1). There was a significant difference in preference for error correction between Yes (97\%) and No (3\%) responses. However, the result of the logistic regression showed that the avoidant learning style variable was significant at 0.05 significance level with a Wald statistic of $\mathrm{Q}_{\mathrm{w}}=4.12$. The odds ratio indicated that subjects with avoidant learning styles are have 10 times lower odds of preferring consistent correction of errors. This finding indicates that students who are not enthusiastic about learning content and attending class do not like receiving error correction, though most students expressed preferences for consistent correction.

Second, characteristics of learning styles affected some results directly. For example, the results of correlation and logistic regression analyses showed that subjects with collaborative learning styles prefer peer and self-correction, judging from the result that those with the collaborative learning style prefer being corrected by "Instructor and Peer" $\left(\underline{\mathrm{r}}=.26, \mathrm{p}<.05 ; \mathrm{Q}_{\mathrm{w}}=4.34, \mathrm{p}<.05-285.6\right.$ times higher odds $)$, "Instructor, Peer, and Yourself” $\left(\underline{\mathrm{r}}=.20, \mathrm{p}<.05, \mathrm{Q}_{\mathrm{w}}=3.99\right.$, $\mathrm{p}<.05-7.8$ times higher odds), and "Yourself" $(\underline{\mathrm{r}}=.25, \mathrm{p}<.05)$, but not "Instructor" $(\underline{\mathrm{r}}=-.32, \mathrm{p}<.01)$. On the other hand, those with the diligent learning style prefer self-correction $(\mathrm{r}=.22, \mathrm{p}<.05)$ (these findings concern Question 2).

Third, the finding revealed a problem regarding the use of a correction code. The correction code is usually made by a grammatical item list (e.g., noun, particle, pronoun, preposition, etc.), encouraging students to correct errors themselves. The result of correlation analysis showed that those with the diligent learning style prefer receiving error correction by coding system ( $\mathrm{r}=.23, \underline{\mathrm{p}}<.05)$ (Question 6). Those with the avoidant learning style, however, do not prefer receiving grammar correction by coding system, as revealed in the correlation analysis $(\mathrm{r}=-.23, \mathrm{p}<.05)$. Those with the collaborative learning style do not prefer grammar $\left(\mathrm{Q}_{\mathrm{w}}=4.42, \mathrm{p}<.05-2.9\right.$ times lower odds $)$ and particle corrections $(\mathrm{r}=$ $-.23, \mathrm{p}<.05 ; \mathrm{Q}_{\mathrm{w}}=4.22, \mathrm{p}<.05-2.2$ times lower odds) but like correction for Kanji (Chinese characters) errors ( $\mathrm{r}=.23$, $\mathrm{p}<.01 ; \mathrm{Q}_{\mathrm{w}}=5.58, \mathrm{p}<.05-9.2$ times higher odds). These results indicate that it might be easy for learners to correct characters such as Kanji (Chinese characters) but difficult to correct errors marked by a coding system, except

TABLE 3

THE RELATIONSHIP BETWEEN LEARNERS' FACTORS RELATED TO LEARNING (LEARNING STYLES AND EPISTEMOLOGICAL BELIEFS) AND ERROR FEEDBACK QUESTIONS DURING WRITING ACTIVITIES INFLUENCED MORE BY SOCIAL CONSTRUCTIONS IN THE CLASSROOM

\begin{tabular}{|c|c|}
\hline Error Correction Question & $\begin{array}{l}\text { Significant Result } \\
\text { Leaming Style }\end{array}$ \\
\hline $\begin{array}{l}\text { Q2: When your errors are corrected, } \\
\text { (Instructor 87\%, Instructor } \\
\text { Yourself 1\%) } \\
\text { Instructor } \\
\\
\text { Instructor \& Peer } \\
\text { Instructor \& Yours elf } \\
\text { Instructor, Peer \& Yourself } \\
\text { Yourself }\end{array}$ & $\begin{array}{l}\text { tou generally prefer to receive the error correction? } \\
\text { tructor and Yourself } 1 \% \text {, Instructor, Peer, and Yourself } 7 \% \text {, } \\
-{ }^{\text {b Collaborative }} \\
\text {-Avoidant } \\
+{ }^{\text {a }} \text { Collaborative } \\
+ \text { Co llaborative } \\
\text {-Co llaborative } \\
+ \text { Diligent }\end{array}$ \\
\hline
\end{tabular}

Note. $\quad+$ a indicates positive attitudes. -b indicates negative attitudes. 
TABLE 4

THE RELATIONSHIP BETWEEN LEARNERS' FACTORS RELATED TO LEARNING (LEARNING STYLES AND EPISTEMOLOGICAL BELIEFS) AND ERROR FEEDBACK QUESTIONS DURING WRITING ACTIVITIES INFLUENCED BY INDIVIDUAL LEARNERS' INTERNALIZING PROCESSES

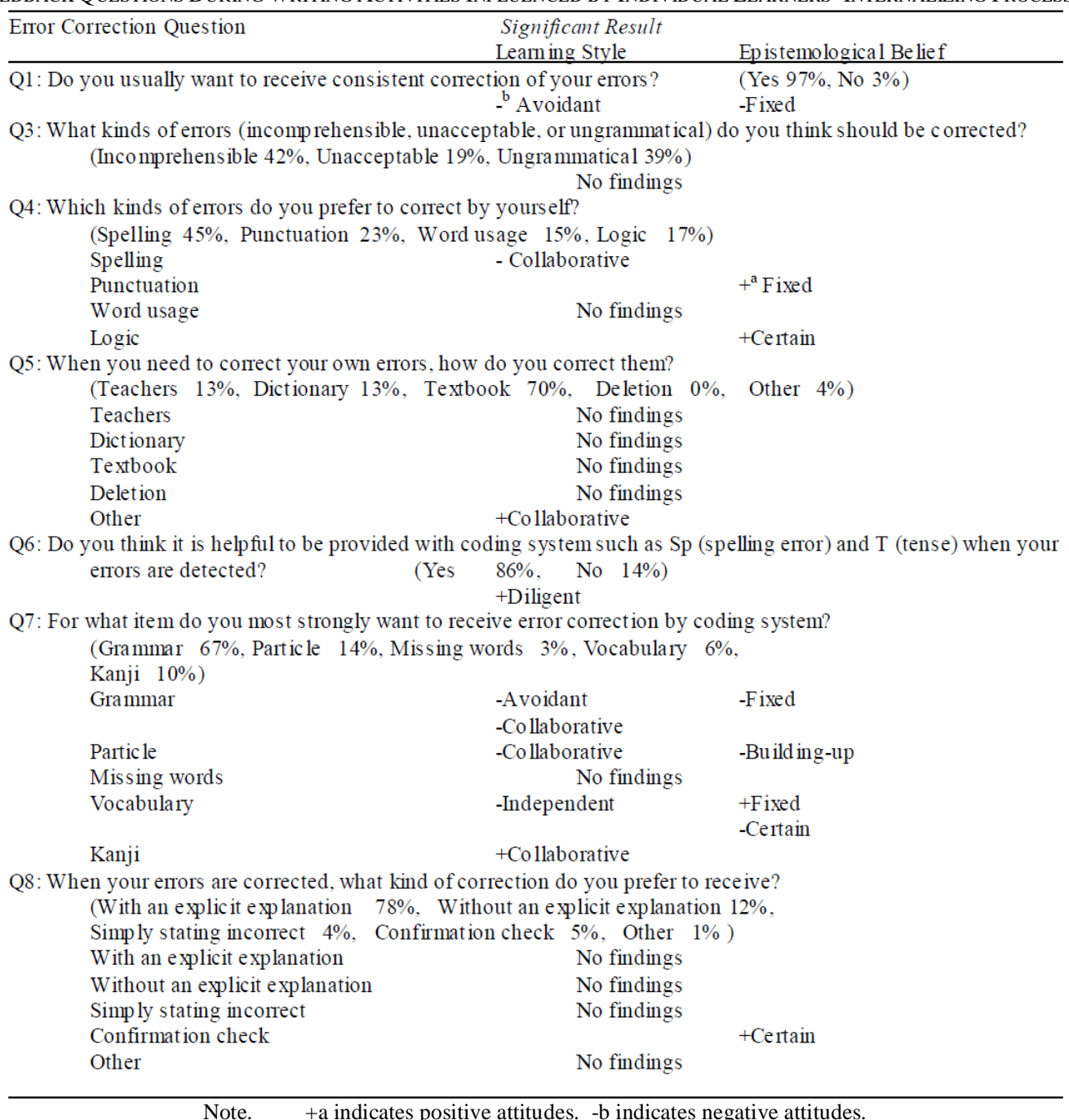

for those who have diligent learning style. Some previous studies also pointed out the problems of using a coding system to provide error feedback. For example, Berry (1995) found a big gap between teachers and learners' knowledge of metalinguistic terms. Lee's study (1997) showed that students' ability to describe errors using appropriate grammatical categories was limited. Lee's study (2004) also found that $91 \%$ of secondary school students indicated that their teachers used error codes to mark their writing even though a number of students did not always fully understand the codes. These research findings suggest that teachers need to carefully observe students' analytical abilities regarding grammar when a coding system is used to provide error feedback.

Study Two Part 2: The Relationship between Epistemological Beliefs and Learners' Perceptions of Error Feedback.

The results of previous studies on epistemological beliefs revealed that beliefs about learning are "linked to persistence in the face of difficult tasks, anticipated time investment for problem solving, comprehension, metacomprehension, overall attitude toward the benefits of an academic education, and coping with everyday life" (Schommer, 1998b, p. 136). The epistemological belief questionnaire elicits the learners' preferences, tendencies, and habits while accounting for individual differences in learning. On the contrary, the questionnaire items in the GrashaRiechmann Student Learning Style Scales (1994) identify students' learning styles, attitudes, and feelings towards the classroom climate. The findings also revealed that aspects of learners' individual differences in acquiring processes of knowledge rather than social aspects affected by the classroom environment influence the relationship between epistemological beliefs and learners' perceptions of error feedback (see Table 3 and 4).

First, as mentioned in the previous section, the study found an overall positive attitude toward error feedback (Question 1). However, the fixed ability belief variable was statistically significant, with a significance level of 0.05 and a Wald statistic of $\mathrm{Q}_{\mathrm{w}}=4.03$. For the fixed ability belief, lower odds of 100 indicates that subjects who had the fixed ability epistemological belief were 100 times less likely to prefer consistent correction of errors. Considering four epistemological belief categories, this result can be interpreted that only students who believe that knowledge and ability are fixed from the beginning do not like receiving error correction. 
The second finding regarding the relationship between epistemological beliefs and error feedback shows the consistency of learners' perceptions across oral and writing activities. A finding of the relationship between learners' epistemological beliefs and their perceptions of error feedback during oral activities revealed that learners with building-up ability prefer receiving error correction during grammar practice in Study 1. In terms of writing activities, the correlation and logistic regression analyses revealed that learners who have the fixed ability belief do not prefer grammar correction $\left(\underline{r}=-.26, \underline{p}<.01, \mathrm{Q}_{\mathrm{w}}=6.03, \underline{\mathrm{p}}<.05-3.7\right.$ times lower odds). In contrast to the fixed ability belief, the building-up ability belief contradicts the belief that abilities are fixed at birth. Both of these results support the belief that it is possible to acquire indefinite, complicated, and uncertain knowledge through long-term learning experiences, might be required for accepting error feedback regarding grammar and for an eagerness to learn the language.

Third, different phenomena of learners' perceptions in terms of epistemological beliefs were observed depending on the type of activity (i.e., oral or writing activity). For example, Study 1 showed that certain knowledge learning style learners prefer error feedback without explicit explanations during oral activities more compared to those who had other epistemological beliefs. Correlation and logistic regression analyses showed that learners who have certain knowledge belief would like to receive a confirmation check during writing activities $\left(\underline{r}=.23, \underline{p}<.05 ; \mathrm{Q}_{\mathrm{w}}=3.88, \underline{\mathrm{p}}<.05--8.2\right.$ times higher odds). These results could indicate that learners who believe that they can learn certain knowledge with an effort might want to correct errors after receiving a confirmation check during writing, but might not like to be corrected without explicit explanations during oral activities. The difference between the spontaneous nature of oral activities and the long period involved in the planning, drafting, and editing process of writing activities might have affected these results. Another difference in their preference of error correction styles between oral and writing activities could be attributed to a higher degree of cognitive process involved in writing activities compared to oral activities. In writing activities, students can actually read what they wrote and review the written feedback. This visual aid should ease the students' understanding of the feedback and correcting their own errors easier.

Study Two Part 2: The Relationship between Learners' Demographic Information and Learners' Perceptions of Error Feedback.

In Study 2, the relationship between learners' demographic information and learners' perceptions of error feedback revealed two primary findings (see Table $5 \& 6$ ).

First, demographic information relates more to learners' perceptions of error feedback in writing activities as compared to oral activities (Table $7 \& 8$ ). The relationship between demographic information and learners' perceptions of error feedback found in Study 1 shows that proficiency levels influence the learners' preferences for error feedback. This finding supports previous studies on the effects of error feedback in the classroom (e.g., Day, Chenoweth, Chun, \& Luppescu, 1984; Flick, 1980; Salo-Lee, 1991). In Study 1, higher levels of learners' proficiency correlated negatively with preferences for self-correction and positively with peer-correction. In addition, higher proficiency levels of learners are associated with preference for error feedback during more global and integrative classroom activities, whereas the lower proficiency levels are associated with preference for error feedback during more discrete point activities.

In Study 2, which investigated preference for error feedback with regard to writing activities, ethnicity and major were more likely to relate to learners' perceptions of error feedback (Table $5 \& 6$ ). For instance, white ethnic learners had a negative perception of receiving error feedback only for incomprehensible errors or for errors that are unacceptable even if they are comprehensible. This means that white ethnic learners might want to receive feedback for ungrammatical errors even if those errors are acceptable and comprehensible, and such learners are strictly concerned about grammatical accuracy (Question 3). Chi-square tests revealed that Asian ethnic learners perceived error feedback provided using the coding system positively $\left(\chi^{2}=4.60, \underline{p}<.05\right)$. As mentioned previously, it is a cognitively demanding

TABLE 5

THE RELATIONSHIP BETWEEN LEARNERS’ DEMOGRAPHIC INFORMATION AND ERROR FEEDBACK QUESTIONS DURING WRITING ACTIVITIES INFLUENCED MORE BY SOCIAL CONSTRUCTIONS IN THE CLASSROOM

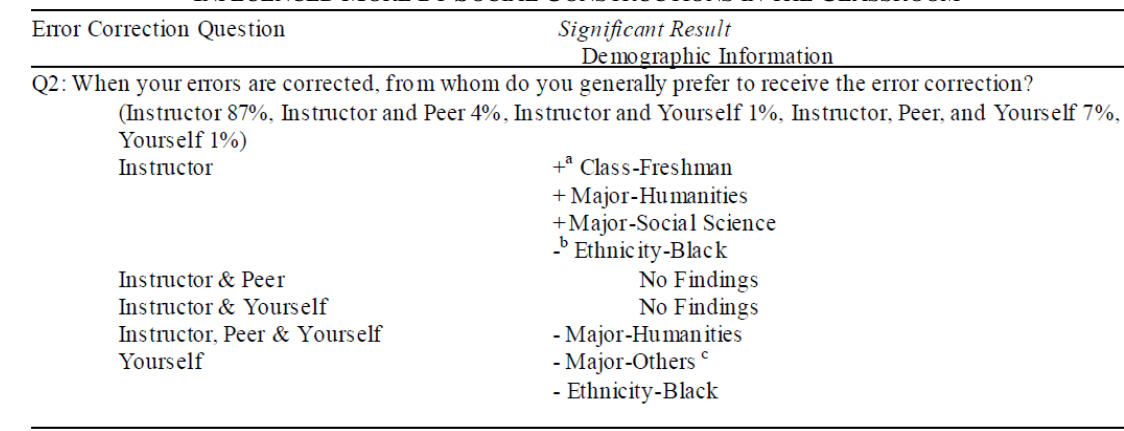

Note. $\quad+a$ indicates positive attitudes. -b indicates negative attitudes.

Major-Others c indicates students' majors other than Humanities, Social Science, Engineering, and Sciences.

task to understand and correct errors marked by coding; however, this result indicates that Asian ethnic learners have an ability to understand metalinguistic terminology and a tendency to make an effort at corrections (Question 6). 
Second, the correlation analysis of the present study showed that higher proficiency levels of learners are associated with their preference to correct errors by themselves using dictionaries $(\underline{r}=.20, \underline{p}<.05)$. This result could suggest that learners with higher proficiency levels are accustomed to using dictionaries.

\section{DisCUSSION}

A comparison of learners' perceptions of error feedback in writing activities with learners' perceptions of error feedback in oral activities revealed three significant findings.

First, the findings support the hypothesis of this study. Error feedback concerning writing activities had a greater relationship with factors affected by learners' background and beliefs, which influence how individuals understand the nature of cognitive tasks and decide their strategies to deal with them (Kitchener, 1983), rather than with learning styles that would be affected by such social aspects as interaction with peers and the instructor in the classroom. Based on the results of correlation and logistic regression analyses of learners' perceptions of error feedback during oral activities, the number of relationships between learners' perceptions of error feedback and learning styles, which reached the statistical significance level, was three times greater than the number of relationships between learners' perceptions of error feedback and epistemological beliefs. In contrast, regarding writing activities, the number of statistically significant relationships between learners' perceptions of error feedback and learning styles was two times greater than the number of statistically significant relationships between learners' perceptions of error feedback and epistemological beliefs. Furthermore, demographic information, which describes learners' educational and cultural backgrounds, related more to learners' perceptions of error feedback than did epistemological beliefs and learning styles in writing activities (Table $7 \& 8$ ).

Second, the study revealed that different environmental natures of oral and written activities influence some results. For instance, more students preferred to receive correction for unacceptable errors only during oral activities rather than during writing activities ( $31 \%$ and $19 \%$, respectively), whereas more students preferred to receive correction for ungrammatical errors during writing activities instead of oral activities (39\% and 23\%, respectively. This result suggests that learners believe that writing tasks are more likely to emphasize accuracy, whereas oral activities are more likely to emphasize communication flow.

Third, similar results for oral and writing activities were also found. Many studies revealed that both teachers and students prefer comprehensive error correction focused on grammar, regardless of whether or not it has long-term significance. A preference for consistency of grammatical error correction for both oral and writing activities was shown (99\% and 97\%, respectively). In addition, the dominant preference was receiving error correction for grammar (grammar practice during oral activities: 52\%; grammar by coding system during writing activities: 67\%). 
TABLE 6

THE RELATIONSHIP BETWEEN LEARNERS' DEMOGRAPHIC INFORMATION AND ERROR FEEDBACK QUESTIONS DURING WRITING ACTIVITIES INFLUENCED BY INDIVIDUAL LEARNERS' INTERNALIZING PROCESSES

\begin{tabular}{lc}
\hline Error Correction Question & $\begin{array}{c}\text { Significant Result } \\
\text { Demographic Information }\end{array}$ \\
\hline Q1: Do you usually want to receive consistent correction of your errors?
\end{tabular}

$$
\text { (Yes } 97 \% \text {, No 3\%) }
$$

Q3: What kinds of errors (incomp rehensible, unacceptable, or ungrammatical) do you think should be corrected? (Incomprehensible 42\%, Unacceptable 19\%, Ungrammatical $39 \%$ ) Incomprehensible $\quad{ }^{\mathrm{b}}$ Ethnicity-White Unacceptable -Ethnicity-White -Class-Freshman -Profic iency level-Intermed iate Ungrammatical

Q4: Which kinds of errors do you prefer to correct by yours elf? (Spelling 45\%, Punctuation 23\%, Word usage $15 \%$, Log ic $17 \%$ ) Spelling - Major-Social Science Punctuation Word usage -Class-Master -Major-Social Science -Major-Eng ineering, Sciences + Ethnicity-Hispanic Logic -Proficiency level-High

Q5: When you need to correct your own errors, how do you correct them?

$\begin{array}{lrl}\text { (Teachers } & 13 \%, \text { Dictionary } 13 \%, \text { Textbook } & 70 \%, \text { Deletion } 0 \%, \text { Other } 4 \%) \\ \text { Teachers } & \text { - Ethnicity-Black } \\ & \text { - Ethnicity-Hispanic } \\ \text { Dictionary } & \text { + Class-Master } \\ & \text { + Proficiency Level } \\ \text { Textbook } & \text { No findings } \\ \text { Deletion } & \text { No findings } \\ \text { Other } & \text { No findings }\end{array}$

Q6: Do you think it is helpful to be provided with coding system such as Sp (spelling error) and T (tense) when you $\begin{array}{ll}\text { errors are detected? } & \text { (Yes } 86 \% \text {, No } 14 \% \text { ) }\end{array}$ + Ethnicity-Asian

Q7: For what item do you most strongly want to receive error correction by coding system? (Grammar $67 \%$, Particle $14 \%$, Missing words $3 \%$, Vocabulary $6 \%$, Kanji $10 \%$ ) Grammar

Particle No findings

Missing words

Vocabulary

No findings No findings

-Class-Freshman

-Ethnicity-White Kanji -Ethnicity-White

Q8: When your errors are corrected, what kind of correction do you prefer to receive?

(With an explicit exp lanation $78 \%$, W ithout an explic it explanation $12 \%$, Simply stating incorrect $4 \%$, Confirmation check $5 \%$, Other $1 \%$ ) With an explicit explanation

- Class-Doctorate

+ Major-Engineering, Sciences

Without an explicit explanation

- Major-Social Sciences

- Major-Engineering, Sc iences

Simply stating incorrect Confirmation check

- Class-Freshman

+ Class Level

Other

-Maior-Others Note. $+\mathrm{a}$ indicates positive attitudes. - b indicates negative attitudes.

TABLE 7

NUMBER OF LEARNERS' CHARACTERISTICS SIGNIFICANTLY RELATED TO PERCEPTIONS OF ERROR FEEDBACK IN ORAL ACTIVITIES

\begin{tabular}{|l|l|l||l|}
\hline & Perceptions by Social Aspects & $\begin{array}{l}\text { Perceptions by Individual } \\
\text { Aspects }\end{array}$ & Total \\
\hline Learning Styles & $11(52.4 \%)$ & $10(47.6 \%)$ & $21(53.8 \%)$ \\
\hline Epistemological Beliefs & $2(2.9 \%)$ & $5(7.1 \%)$ & $7(18.0 \%)$ \\
\hline Demographic Information & $7(63.6 \%)$ & $4(36.4 \%)$ & $11(28.2 \%)$ \\
\hline \hline Total & $20(51.3 \%)$ & $19(48.7 \%)$ & $39(100 \%)$ \\
\hline
\end{tabular}

aNumber of learners' characteristics significantly related to perceptions of error feedback affected by social aspects. The results of Questions $1-3$ \& 5 (refer to the questions in Table $1 \& 2$ ) are included in this column.

bNumber of learners' characteristics significantly related to perceptions of error feedback affected by individual learning aspects. The results of Questions 4 \& 6-7 (refer to the questions in Table 3-6) are included in this column.

TABLE 8

NUMBER OF LEARNERS' CHARACTERISTICS SigNIFICANTLY RELATED TO PERCEPTIONS OF ERROR FEEDBACK IN WRITING ACTIVITIES

\begin{tabular}{|l|l|l||l|}
\hline & Perceptions by Social Aspects & $\begin{array}{l}\text { Perceptions by Individual } \\
\text { Aspects }\end{array}$ & Total $^{\text {b }}$ \\
\hline Learning Styles & $6(46.2 \%)$ & $9(20.0 \%)$ & $15(25.9 \%)$ \\
\hline Epistemological Beliefs & $0(0 \%)$ & $9(20.0 \%)$ & $9(15.5 \%)$ \\
\hline Demographic Information & $7(53.8 \%)$ & $27(60.0 \%)$ & $34(58.6 \%)$ \\
\hline \hline Total & $13(22.4 \%)$ & $45(77.6 \%)$ & $58(100 \%)$ \\
\hline
\end{tabular}




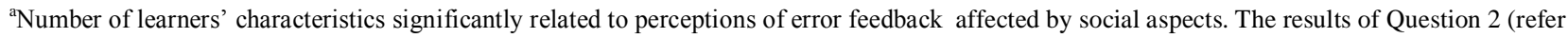
to the questions in the paper) are included in this column.

'Number of learners' characteristics significantly related to perceptions of error feedback affected by individual learning aspects. The results of all questions except Question 2 are included in this column.

\section{Pedagogical IMPLiCATions}

The ultimate goal of this study is to recommend to foreign language instructors, especially instructors of Japanese as a second language, suitable methods of providing error feedback to students with different backgrounds, learning styles, and epistemological beliefs. Instructors should not claim that one universal approach to error feedback solves problems for all learners; therefore, these studies were pedagogically motivated to identify the learners' characteristics and their perceptions of error feedback and to find the error feedback method tailored to each individual.

The suggested pedagogical issue is to identify educational and cultural backgrounds of students, their learning styles, and their beliefs about learning. Instructors can then select which error feedback methods to use for their students. The present study showed that the manner in which learners' factors (learning styles, epistemological beliefs, and demographic information) relate to learners' perceptions of error feedback can be explained using error feedback questions that explore both how learners react to social aspects in class settings and how perceptions would be affected by learners' beliefs regarding the acquisition of knowledge. Table 8 lists learners' factors, such as learning styles and epistemological beliefs, which were significantly related to perceptions of error feedback in writing activities. It shows that the relationship between learning styles and learners' perceptions of error feedback shows that learning styles rather than epistemological beliefs are more closely related to perceptions of error feedback affected by social aspects; however, epistemological beliefs and learning styles are equally related to their perceptions of error feedback affected by individual learning aspects. Moreover, Table 8 shows that demographic information is the most influential factor of how learners perceive error feedback in writing activities. Although the same numbers of learning styles and epistemological beliefs are related to learners' perceptions as are influenced by aspects of individual learning, the number of relationships between learners' perceptions of error feedback and learning styles during oral activities, which is statistically significant, is three times greater than the number of relationships between learners' perceptions of error feedback and epistemological beliefs (Table 7). In contrast, regarding writing activities, the number of statistically significant relationships between learners' perceptions of error feedback and learning styles is two times greater than the number of statistically significant relationships between learners' perceptions of error feedback and epistemological beliefs (Table 8). These findings suggest that it is necessary for instructors to select error feedback methods based on the types of activities involved while considering that social aspects, individual aspects, or learners' original backgrounds influence these activities.

\section{CONCLUSIONS}

These studies attempted to cross-validate learners' perceptions of error feedback in writing and oral activities by integrating psychological theories. Pedagogically, the findings of two studies in this article could suggest ways for foreign language teachers, especially teachers of Japanese as a foreign language, to develop appropriate methods of error feedback for students with different backgrounds, learning styles, and epistemological beliefs, both for oral and writing activities. Furthermore, the findings of these studies could suggest two steps involved in finding a solution to error feedback problems, though the real classroom settings are not dichotomously separated by individual and social variables as mentioned previously. The first step is to identify students' characteristics regarding their dispositions of learning as well as their demographic information. The second step is to consider whether the problematic issues exist in individual learners or in the social construction of the classroom. However, this investigation was conducted mainly from learners' perspectives of feedback. Therefore, further studies could explore error feedback strategies from instructors' perspectives and analyze long-term effectiveness of each error feedback strategy.

\section{ApPendix A Questionnaire Part Two-Learners' Perceptions of Error Feedback During Oral Activities}

1. Do you usually want to receive consistent correction of your errors? Please circle one.

$$
\text { Yes No }
$$

2. When your errors are corrected, from whom do you generally prefer to receive the error correction? Please circle one.

Instructor Fellow students Yourself

3. After your instructor states that your utterances were incorrect, do you want to correct them by yourself? Please circle one. Yes

4. When do you want to receive the error correction? Please circle one. Immediately after making an error After finishing a conversation

5. During what kind of classroom activity do you most want to receive the error correction? Please circle one. 

Pronunciation practice
Grammar practice
Skit
Free conversation

6. What kinds of errors do you think should be corrected in class? Please circle one.

a. All incomprehensible errors

b. If the errors are unacceptable, even if they are comprehensible.

c. If the errors are ungrammatical, even if they are acceptable and comprehensible.

7. For what grammatical items do you want to receive the error correction the most?

Please circle one.

Pronunciation Particles Conjugation of verbs or adjectives

Usage of words Logical coherence

8. When your errors are corrected, what kind of correction do you prefer to receive? Please circle one.

a. Receiving a correct utterance with an explicit explanation

b. Receiving a correct utterance without an explicit explanation

c. Simply stating that your utterance was incorrect

d. Receiving a confirmation check by repeating your incorrect utterance with rising intonation

\section{ApPendix B Questionnaire Part Two-Learners' Perceptions of Error FeEdBack During Writing ACTIVITIES}

1. Do you usually want to receive consistent correction of your errors?

Yes No

2. From whom do you want to receive error correction?

Instructor

Peer Yourself

3. What kinds of errors (incomprehensible, unacceptable, or ungrammatical) do you think should be corrected?

a. incomprehensible errors

b. unacceptable errors

c. ungrammatical errors

4. Which kinds of errors do you prefer to correct by yourself? Spelling Punctuation Word usage Logic

5. When you need to correct your own errors, how do you correct them?

a. ask teacher for help

b. check a dictionary

c. check a textbook

d. delete sentences which contain errors

e. other

6. Do you think it is helpful to be provided with coding system such as Sp (spelling error) and T (tense) when your errors are detected?
Yes
No

7. For what item do you most strongly want to receive error correction by coding system?
Grammar Particle Missing words
Vocabulary
Kanji

8. When your errors are corrected, what kind of correction do you prefer to receive?
a. an explicit explanation
b. without an explicit explanation
c. simply stating "incorrect"
d. a confirmation check
e. other

\section{REFERENCES}

[1] Allwright, R. (1984). The importance of interaction in classroom language learning. Applied Linguistics, 5 (2), 156-171.

[2] Berry, R. (1995). Language teachers and metalinguistic terminology. Paper presented at the Third International Conference on Teacher Education in Second Language Teaching, Hong Kong.

[3] Breen, M. P. (2001). Overt participation and covert acquisition in the language classroom. In M.P. Breen (Ed.), Learner contributions to language learning (pp. 112-140). London: Longman.

[4] Carroll, J., \& Swain M. (1993). Explicit and implicit negative feedback. SSLA, 15, 357-386.

[5] Chan, K. (2007). Hong Kong teacher education students' epistemological beliefs and their relations with conceptions of learning and learning strategies. The Asia Pacific-Education Researcher, 16(2), 199-214.

[6] Cohen, A. (1984). Studying second-language learning strategies: how do we get the information? Applied Linguistics, 5, 101112.

[7] Crichton, J. (1990). 'Crisis points' in error correction. Sydney, Australia: Macquarie University.

[8] Day, R.R., Chenoweth, N.A., Chun, A.E., \& Luppescu, S. (1984). Corrective feedback in native-nonnative discourse. Language Learning, 34 (2), 19-45.

[9] Ellis, R. (1994). The study of second language acquisition. Oxford: Oxford University Press. 
[10] Ellis, R. (2008). The study of second language acquisition. Second edition. Oxford: Oxford University Press.

[11] Ferris, D. A. (2002). Treatment of error. Ann Arbor, MI: The University of Michigan Press.

[12] Flick, W. C. (1980). Error types in adult English as a second language. In B. Kettemann \& R. N. St. Clair (Eds.). New approaches to language acquisition (pp. 57-64). Mikrocard, Offset verboten, Germany: Gunter Narr Verlag Tubingen.

[13] Gass, S. M. and Mackey, A. (2000) Stimulated recall methodology in second language research. Mahwah, NJ: Lawrence Erlbaum.

[14] Grasha, A. F. (1972). Observations on relating teaching goals to student responses styles and classroom methods. American Psychologist, 27, 144-147.

[15] Grasha, A. F. (1996). Teaching with style. Pittsburgh, PA: Alliance Publishers.

[16] Grasha, A. F., \& Riechmann, S. (1994). Grasha-Riechmann student learning style scales. Cincinnati, OH: University of Cincinnati.

[17] Han, Z., \& Selinker, L. (1999). Error resistance: Towards an empirical pedagogy. Language Teaching Research, 3(3), 248-275.

[18] Kitchener, K. S. (1983). Cognition, metacognition, and epistemic cognition. A three-level model of cognitive processing. Human Development, 26, 222-232.

[19] Kubota, M. (2001). Error correction strategies used by learners of Japanese when revising a writing task. System,29, 467-480.

[20] Lee, I. (1997). ESL learners' performance in error correction in writing: Some implications for teaching, System, 25(4), 465-477.

[21] Lee, I. (2004). Error correction in L2 secondary writing classrooms: The Case of Hong Kong. Journal of Second Language Writing, 13, 285-312.

[22] Nobuyoshi, J., \& Ellis, R. (1993). Focused communication tasks and second language acquisition. ELT Journal, 47 (3), $203-$ 210.

[23] Panova, L., \& Lyster, R. (2002). Patterns of corrective feedback and uptake in an adult ESL classroom. TESOL Quarterly, 36, 573-595.

[24] Rubin, J. (1975). What the "good language learner" can teach us. TESOL Quarterly, 9, 41-51.

[25] Russell, J., \& Spada, N. (2006). The Effectiveness of Corrective Feedback for the Acquisition of L2Grammar: A Meta-analysis of the Research. In J. Norris and L. Ortega (Eds.), Synthesizing research on language learning and teaching (pp. 133-164). Amsterdam: John Benjamins Publishing.

[26] Salo-Lee, L. (1991). L2 Learners Repairs in Cross-Cultural. In communication and discourse across cultures and languages. AfinLa yearbook 1991.

[27] Salomon, G., \& Perkins, D. N. (1998). Individual and social aspects of learning. Review of Research in Education, $23,1-24$.

[28] Savingnon, S. J. (1983). Communicative competence: Theory and classroom practice. Reading MA: Addison-Wesley Publishing Company.

[29] Schommer, M. (1989). Students' beliefs about the nature of knowledge: What are they and how do they affect comprehension? Unpublished doctoral dissertation, University of Illinois at Urbana-Champaign, Campaign, IL.

[30] Schommer, M. (1990). Effects of beliefs about the nature of knowledge on comprehension. Journal of Educational Psychology, 82(3), 498-504.

[31] Schommer, M. (1998a). The influence of age and education on epistemological beliefs. British Journal of Educational Psychology, 68, 551-562.

[32] Schommer, M. (1998b). The Role of Adults' Beliefs about Knowledge in School, Work, and Everyday Life. In M. Smith, \& T. Pourchot (Eds.), Adult learning and development: perspectives from educational psychology (pp. 127-144). Hillsdale, NJ: Lawrence Erlbaum Associates.

[33] Schommer-Aikins, M. (2001). An Evolving Theoretical Framework for an Epistemological Belief System. In K. Hofer \& P. R. Pintrich (Eds.), Personal epistemology: The psychological of beliefs about knowledge and knowing (pp. 103-118). Mahwah, NJ Lawrence Erlhaum Associates.

[34] Slimani, A. (1989). The role of topicalization in classroom language learning. System, 17, 223-234

[35] van Lier, L. (1988). The classroom and the language learner. London: Longman Group.

Noriko Fujioka-Ito was born in Japan. She earned $\mathrm{Ph}$. D. and MA degrees majoring in foreign and second language education with Japanese linguistics and educational research minors from the Ohio State University, USA.

She has been teaching and coordinating Japanese courses of the McMicken College of Arts \& Sciences at the University of Cincinnati (UC), Ohio, USA. She is also a director of the Japanese Language and Culture Program at UC. She has published in the journals such as Japanese Language Education around the Globe, the Journal of Canadian Association for Japanese Language Education, Intercultural Communication Studies, and The Japan Association for Language Teaching Journal of Japanese Language Education. Her research interests include learner autonomy, learners' perceptions of error feedback, and distance-learning education.

Dr. Fujioka-Ito is a member of several academic organizations such as the American Association for Applied Linguistics, the American Council on the Teaching of Foreign Languages, the Association of Teachers of Japanese, and The Japan Association for Language Teaching. 